\title{
Family engagement as part of managing patients with mental illness in primary care
}

\author{
Hatta Santoso $\underline{\text { Ong }}^{1,2}$, MBBS, MRCPsych, Paula Ann $\underline{\text { Fernandez }}^{3}$, BA, BSocSci(Hons), Hui Khim $\underline{\text { Lim }}^{1}$, MSocSci
}

\begin{abstract}
The family unit plays a crucial role in patients with mental illness. Mental health problems have been associated with an assortment of dysfunctional social and psychological processes in one's family of origin, yet families are now expected to be responsible for the care of the patient with mental illness. There are many short- and long-term benefits of engaging the families in the care of patients with mental illness. However, the implementation of family engagement in patients with mental illness is fraught with challenges. The primary care provider possesses several distinctive characteristics that lend an advantage to successfully engaging the families of patients with mental illness, such as better accessibility, better rapport, and being associated with less stigma. Primary care providers could engage the family in various ways, ranging from basic functions such as psychoeducation and supporting the family's needs, to more specialised interventions such as family assessment and family therapy.
\end{abstract}

Keywords: carer engagement, family engagement, family interventions, primary care, primary mental healthcare

\section{INTRODUCTION - FAMILY AND MENTAL HEALTH}

We are influenced tremendously by our family of origin. From the time we are born, we begin to form early attachments to our primary carers. This need for connection and attachment to others continues throughout our lifespan. Our families shape us - they influence our development, and we model their behaviours and habits. We look to our families for shelter, support and provision of resources. We instinctively expect our families to be available for us in our time of need.

For patients with mental illness, the family unit plays an even more crucial role. Mental health problems have been associated with an assortment of social and psychological processes in one's family of origin. These include parental conflict and affection, ${ }^{(1-5)}$ emotional detachment from parents, ${ }^{(6,7)}$ parenting style, ${ }^{(8,9)}$ time spent with family, ${ }^{(10)}$ family cohesion ${ }^{(11)}$ and perceived family support. ${ }^{(12-15)}$ Low socioeconomic status of the family and exposure to social stress have also been found to be correlated with poorer mental health. ${ }^{(16)}$ With the deinstitutionalisation of mental health services over the past few decades, families are now expected to be the primary carers of patients with mental illness. As a result, families have often felt blamed for mental health problems and laden with the responsibility of providing support. ${ }^{(17)}$

\section{FAMILY AS CARERS FOR PATIENTS WITH MENTAL ILLNESS}

Over the last four to five decades, psychiatric care has evolved from the former asylum system of care to that of 'care in the community'. This has resulted in a trend towards engaging patients and their families and carers in the management of their mental illness. Family engagement has been defined as "the process of identifying, enrolling and retaining families in treatment services". ${ }^{(18)}$ The terms 'carer' and 'caregiver' usually refer to the "substantial, yet 'non-professional' role that individuals in a close relationship have in supporting a person receiving mental health treatment" ${ }^{(19)}$ In Singapore, the carer of a patient is usually a family member. ${ }^{(20,21)}$ It is now widely accepted that it is necessary to acknowledge the personal experiences of patients and their families during the planning and organising of psychiatric care. The World Psychiatric Association (WPA), in its Task Force on Best Practice in Working with Service Users and Carers, ${ }^{(22)}$ has recommended that clinical psychiatric care of any person in acute or rehabilitation situations should be done in collaboration among the user, the family or carer, and the clinicians. The World Health Organization's Mental Health Action Plan (2013-2020) also called for greater collaboration with families in the delivery of mental health services. ${ }^{(23)}$ The Royal College of Psychiatrists (RCPsych) has made it a priority to strengthen the involvement of service users and carers in the planning of services and in research initiatives. ${ }^{(24)}$ As a result, the RCPsych regularly involves local carers' groups in their audits of mental health services. Closer to home, the Singapore 3rd Enabling Masterplan 2017-2021 ${ }^{(25)}$ recognises the importance of family members and carers of people with mental disabilities such as autism by including 'Supporting caregivers' as a key thrust. This included recommendations to improve carers' well-being and enhance their carer capabilities, and to support carers in future care planning.

\section{BENEFITS OF FAMILY ENGAGEMENT IN PATIENTS WITH MENTAL ILLNESS}

This movement towards engaging families and carers of people with mental illness has been driven by research, which demonstrated both short- and long-term benefits of this approach. Family

${ }^{1}$ Department of Psychological Medicine, ${ }^{2}$ Department of Sleep Medicine, Surgery and Science, Changi General Hospital, ${ }^{3}$ Singhealth Polyclinics, Singapore Correspondence: Dr Hatta Santoso Ong, Associate Consultant Psychiatrist, Department of Psychological Medicine, Changi General Hospital, 2 Simei Street 3 , Singapore 529889. hatta.santoso.ong@singhealth.com.sg 
engagement in patients with mental illness could lead to better patient outcomes, such as fewer relapses, ${ }^{(26-31)}$ longer duration between relapses, ${ }^{(30)}$ reduced hospital admissions, ${ }^{(26,32-34)}$ shorter inpatient stays, ${ }^{(35,36)}$ and improved compliance to medication and treatment plans. ${ }^{(32,37)}$ For patients with schizophrenia, family engagement has also been shown to lessen residual psychotic and deficit symptoms, ${ }^{(28,33)}$ as well as helping with earlier detection of warning signs of relapse. ${ }^{(38)}$ For patients with depression, early intervention involving the family when symptoms first emerge may help to reduce the severity of the episodes. ${ }^{(39)}$ Family engagement is associated with better self-reported quality of life by patients ${ }^{(40,41)}$ and reduced general social impairment. ${ }^{(32,33,42)}$ There is evidence that these benefits endure over time if family engagement is actively maintained. ${ }^{(29,43-45)}$ Families could also help patients gain access to mental health services during times of crisis. ${ }^{(46,47)}$ Family engagement does not merely benefit the patients, but extends to the family and carers as well. Studies have shown that family engagement helps to ease family burden and carer stress, ${ }^{(31,48-50)}$ as well as reducing expressed emotions in family members and carers. ${ }^{(34)}$

\section{CHALLENGES OF FAMILY ENGAGEMENT}

Despite the well-documented potential benefits of family engagement in the care of patients with mental illness, there have been many reports of difficulties with the implementation of family engagement in routine psychiatric care. A systematic review by Eassom et al indicated that the challenges in implementing family engagement in the treatment of patients with mental illness extended beyond those generally associated with translating research into practice. ${ }^{(19)}$

Patients with mental illness may have reservations towards engaging their families in their treatment for several reasons. Patients may prefer to keep the extent and details of their illness from their family. This preference may be borne out of not wanting to burden the family members, ${ }^{(51,52)}$ or the fear of making the situation worse. ${ }^{(52)}$ These concerns may be valid, especially if the family members are hostile and critical, which could be a source of stress and a trigger for relapse. The patients could also have concerns about privacy and confidentiality. ${ }^{(52)}$ Patients could feel exposed and vulnerable when their problems are laid open to their family. ${ }^{(53)}$ They may also worry that the service providers may inadvertently reveal sensitive personal information to their family members during the process of family engagement. In addition, some patients may have fears about placing their family members in a position of power, ${ }^{(52,54)}$ resulting in an imbalanced relationship in which the family members 'know better'. This, again, could be a valid concern if the family members are the source of stress.

Families of patients with mental illness may have their own concerns about being engaged. Family members could have concerns over their own privacy, ${ }^{(52)}$ especially in cases where family factors are significant contributors to the patient's mental illness. The family may prefer to keep the extent of their family issues from mental health services, to avoid being criticised or blamed for the patient's problems. ${ }^{(55)}$ Some families may want to avoid being burdened by carer stress, perceiving that it would require a lot of time ${ }^{(52)}$ and effort on their part should they be intricately involved. This could be exacerbated if the family members have psychosocial or mental health issues of their own. Other possible barriers to successfully engaging the family in treatment are the lack of understanding of mental illness and the family's role in recovery, ${ }^{(52)}$ as well as the stigma associated with mental illness. ${ }^{(54,56)}$ For some families, their unwillingness to engage could be related to prior negative experiences when working with service providers. Poor rapport with service providers, including feeling patronised and not understood, has also been stated as a reason for their lack of motivation for further engagement. ${ }^{(57)}$

From the perspective of the service providers, barriers to family engagement include fears of burdening the family, ${ }^{(19)}$ increasing professional burden, ${ }^{(52)}$ perceived lack of time and resources, ${ }^{(51,52,56-59)}$ perceived lack of supervision and training, ${ }^{(51,58,59)}$ and self-doubt about one's capabilities in engaging the family. ${ }^{(52,57,58)}$ Some service providers have also cited inadequate whole team commitment and collaboration, resulting in lack of continuity and issues of 'ownership' of the patient and family. ${ }^{(19)}$ In some instances, prevailing negative attitudes towards families as the cause of the mental illness were reasons for service providers' hesitancy to involve the family members. ${ }^{(19,60)}$

In summary, issues of confidentiality, vulnerability, stigma and poor rapport are commonly faced by patients and families during family engagement. For the service providers, apart from the stigma towards families of patients with mental illness, barriers to family engagement include concerns about the lack of time, resources and training to engage the family.

\section{PRIMARY CARE AND ITS ADVANTAGES IN MENTAL HEALTHCARE}

Primary care, or primary healthcare, refers to the provision of universally accessible healthcare to individuals and families in the community, and as close as possible to where people live and work. ${ }^{(61-63)}$ Primary care includes disease treatment, disease prevention, health promotion, rehabilitation and palliative care. ${ }^{(62,63)}$ It encompasses physical, mental, and social health and well-being. ${ }^{(62,63)}$ In Singapore, the term 'primary care providers' usually refers to general practitioners or family physicians in government polyclinics and private medical clinics, as well as allied healthcare professionals such as nurses, psychologists, counsellors and social workers in the primary care setting. Given the multitude of challenges and concerns reported by patients with mental illness, their families and service providers, the proposal of family engagement as part of managing patients with mental illness in primary care may seem like a tall task. However, the primary care provider and the primary care setting possess several unique characteristics that lend an advantage to successfully engaging patients and their families.

\section{Accessibility}

With the increase in lifetime prevalence of mental illness in Singapore, ${ }^{(64)}$ primary care providers have come to play a significant role in the provision of mental healthcare in the 
community. Over the years, Singapore has built up a network of mental healthcare services in the primary care setting in order to improve access to mental health services. ${ }^{(65)}$ The Mental Health General Practitioner (GP) Partnership Programme (MHGPP) has made it possible for GPs to collaborate with tertiary mental health services in the provision of mental health treatment in the community. ${ }^{(65,66)}$ Several polyclinics run mental health clinics manned by primary care physicians who receive guidance and training from psychiatrists. Some polyclinics also have psychologists, counsellors or social workers providing psychological support and counselling for patients with mental illness and their families. In addition, these clinics work together with Community Intervention Teams (COMITs) and Family Service Centres (FSCs) embedded in the community to provide holistic services for patients with mental illness and their families. ${ }^{(65)}$ The accessibility of this network of interdependent mental health services in the community means that service providers could lean on one another for expertise and resources in the provision of holistic psychiatric care to the patient and their families. This ensures that no single primary care provider bears the costs, time and training required for family engagement alone.

This vast network of mental health services in primary care is further boosted by the fact that polyclinics and GP clinics are usually located in the neighbourhoods, which confers greater accessibility and convenience for the patients and their families. This allows the patients and their families to save on transport costs and travel time. ${ }^{(67)}$ Most GP clinics are open on weekday evenings and weekends, which allows for greater flexibility when arranging for a doctor's visit. The proximity and ease of access to the doctor will encourage patients and their families to maintain regular follow-up visits for the management of the patient's mental illness. ${ }^{(67)}$ This would create more opportunities for family engagement. Similarly, the FSCs and COMITs, which are located in neighbourhoods around Singapore, allow allied health professionals to work closely with patients and their families.

\section{Better rapport}

Primary care physicians are multi-skilled and often manage a patient's care needs from 'cradle to grave'. The primary care physician often acts as a stable point of contact for patients and their families for various acute and chronic medical conditions. ${ }^{(67,68)}$ It is not uncommon for a primary care physician to look after the healthcare needs of different generations within the same family. The ease of access and increased opportunities for repeated patient-doctor interactions make it more conducive for rapport-building between patient and doctor. With greater trust in and familiarity with the primary care physician, patients with mental illness may be more willing to share their struggles and seek help for their mental health difficulties. A postal survey ${ }^{(56)}$ conducted among a random sample of GP clinics in Singapore revealed that over $90 \%$ of the GPs who were managing patients with mental illness felt that these patients were more comfortable receiving treatment from them than from a psychiatrist because of their confidence in and familiarity with the GPs. Similarly, family members of patients with mental illness may find asking for help from a primary care physician to be less intimidating than from a psychiatrist. With better rapport among patient, family and doctor, concerns about confidentiality and vulnerability during family engagement may be assuaged. This would make it easier for patients and families to confide in the doctor, increasing the likelihood of successful family engagement.

\section{Less stigma}

In the same postal survey, ${ }^{(56)}$ it was found that the perception of stigma associated with visiting a psychiatrist was one of the leading reasons that patients preferred seeing the GP for issues related to their mental illness. Other reports in the literature ${ }^{(69-73)}$ have also cited stigma as a major factor preventing patients with mental illness from seeking help. Despite efforts to destigmatise mental illness, mental illness is still associated with significant stigma in Singapore. ${ }^{(74,75)}$ This makes the engagement of patients with mental illness and their families more challenging. The prospect of visiting a mental health service provider, be it a psychiatrist, psychologist, social worker or counsellor in a mental health institution or acute hospital, may deter people with mental illness and their families from seeking appropriate treatment and help. Seeking help for mental health issues from a primary care provider in the community may be a more palatable option, as it is not automatically associated with mental illness. With the issue of stigma attenuated, patients with mental illness and their families would be more likely to confide in the primary care provider. This would significantly increase the likelihood of successful family engagement.

\section{WHAT PRIMARY CARE PROVIDERS COULD DO TO ENGAGE THE FAMILY}

Family engagement in mental health services could take several forms, ranging from more basic functions such as providing information, to more specialised interventions such as family therapy. ${ }^{(19)}$ The forms of family engagement that the primary care provider decides to use would depend on the unique characteristics and needs of each patient-family unit, and their motivation and willingness to be engaged.

\section{Psychoeducation}

The primary care provider could take on the role of an educator. Family and patient psychoeducation has been shown to significantly reduce relapse and rehospitalisation rates in patients with mental illness, and reduce the burden and stress level of carers. ${ }^{(76-78)}$ Providing information to family members about the nature of the mental illness suffered by their loved ones could help the family members better understand the difficulties experienced by their loved ones. Psychoeducation could help dispel myths and misconceptions about mental illness. This could help family members better empathise with the patient and avoid blaming the patient for his or her symptoms. Family members could also learn about recognising relapse warning signs and act accordingly to support the patient. This ranges from providing emotional 
support to arranging for an early consultation with the primary care provider or psychiatrist. The primary care provider could also provide guidance to the family on problem-solving skills and crisis management. Psychoeducation could help dissipate some of the stigma surrounding mental illness. As family members become more knowledgeable about mental illness and how they can support their loved ones, they could become stronger pillars of support for the person with mental illness.

\section{Supporting the family's needs}

Caregiving is a rewarding but demanding role. Caring for a family member with mental illness can have negative effects on one's physical health. ${ }^{(79-83)}$ For patients with dementia, family members may need to help the patient with physical tasks, such as dressing, washing, feeding and ambulating. In the process of caring for a mentally ill patient, the family members may neglect their own physical health needs, such as the need for sleep, exercise, dietary nutrition, or tending to their own medical conditions. The primary care provider would be well-placed to routinely enquire about these aspects of physical health during his or her interactions with the carers of patients with mental illness, and provide intervention options and medical support upon understanding their needs.

Caring for a loved one with mental illness can be very stressful due to the chronic nature of many mental illnesses. ${ }^{(84,85)}$ It can be emotionally and mentally draining when one is a carer for a patient with mental illness. ${ }^{(79,81,83)}$ Family members often experience first-hand the challenging behaviours manifested in certain mental illnesses, such as bizarre actions, lack of self-care, self-harming behaviour or suicidality. Family members may even become the targets of aggression or hostility from persons whom they care deeply about. Some family members have difficulty grappling with the loss of their loved ones to mental illness and may harbour unrealistic expectations of how their loved ones should feel or behave. The burden of care, which refers to the impact of a family member's mental illness on the carers' physical health, emotional health and quality of life, has been increasingly recognised and documented over the years. ${ }^{(86-92)}$ Carer burnout can adversely affect the ability of the carer to care for the patient with mental illness.

Primary care providers could help to alleviate carer burnout by providing practical help. For example, the nurse in the polyclinic could engage the family for certain tasks, such as helping to monitor medication compliance, arranging of medical appointments and reminders to attend scheduled medical appointments. Social workers could engage families proactively through frequent contact to check in on their needs, such as through telephone calls or home visits. This could facilitate early identification and resolution of practical problems. With regard to the psychological aspect, enquiring about the emotional state of family members of patients with mental illness could help to screen for family members who are at risk of emotional burnout. The primary care provider could provide simple mental health first aid to the family members, such as supportive counselling to help ease their stress and improve their problem-solving skills and coping mechanisms. Promotion of self-care and instillation of hope are also useful engagement strategies to support family members in the care of their loved ones with mental illness. These tasks could be done via the social workers, psychologists or counsellors in primary care. In some cases, family members may also develop mental illness as a result of the significant stress associated with caring for their loved ones with mental illness. If the primary care provider detects this during his or her interaction with the family member, he or she could initiate a referral to the psychiatrist to help with evaluation and treatment.

People with mental illness and their families are known to face significant social problems such as poverty, unemployment, low educational level and social exclusion. ${ }^{(93-97)}$ These factors could act as predisposing, precipitating and perpetuating factors to the mental illness, and also contribute to the carer stress faced by the family members. The primary care provider, by virtue of his or her intimate knowledge of the family set-up and circumstances, as well as better rapport with the patient and family, would be well positioned to assess the patient and family holistically to identify these problems and render assistance accordingly, such as providing financial assistance or linking them to vocational training and employment opportunities.

Addressing the practical, psychological and social needs of families could help reduce carer burnout and enable families to be better carers for the vulnerable patients with mental illness. In addition, studies have shown that patient and family engagement with mental health services improves when providers adequately tackle these hurdles. ${ }^{(98)}$

\section{Family assessment and therapy}

In order to establish the needs of the patient and family, some form of family assessment is required. Assessing the family helps to determine the types of services that are needed for the family system and the need for monitoring and support, so that the appropriate options and recommendations are explored and offered. This would involve evaluating the family's understanding of the mental illness and how specific areas of family life may be affected by the mental illness. ${ }^{(99)}$ It also involves assessing the family's protective factors, strengths and resources. This is especially helpful in families with complex family dynamics. Family assessment could be done by the social worker in polyclinics or FSCs.

There may also be a role for family therapy in some family systems. Family therapy may be targeted at dysfunctional systemic issues and maladaptive interaction patterns between the family members and the patient, ${ }^{(99)}$ both of which could be perpetuating factors for the patient's mental illness. Family therapy could possibly be offered by skilled psychologists, counsellors or social workers in the polyclinics, FSCs or COMITs.

\section{LOCAL CHALLENGES AND POSSIBLE SOLUTIONS}

Family engagement in primary care is not without its difficulties. Despite the network of mental health services in primary care, some GPs still have reservations about managing patients with mental illness. The postal survey by Vaingankar et al, ${ }^{(56)}$ conducted 
in random GP clinics in Singapore, showed that $65 \%$ of GPs expressed a need for more knowledge on managing patients with mental illness, particularly schizophrenia and addiction disorders. The need for longer consultation times (72\% of GPs) and perceived lack of support services (60\% of GPs) to manage patients with mental illness are other cited difficulties, which may pose a challenge to successful family engagement by the GPs. Specialist-led right-siting of patients with mental illness, such that only patients with milder severity or stable course of mental illness or those in remission are managed in primary care, would help to ensure that primary care providers are not stretched in their capability to provide mental healthcare. Education and training in mental healthcare for GPs, including the Graduate Diploma in Mental Health (GDMH) ${ }^{(100)}$ and continuing medical education activities, could help to increase their capability and confidence in providing mental healthcare in the primary care setting. The Ministry of Health's plan to establish mental health or dementia clinics in 50\% of polyclinics by 2021 and the expansion of the MHGPP to involve more GP clinics $^{(65)}$ would help to enhance the infrastructural resources and capability to treat patients with mental illness and engage their families in primary care.

\section{CONCLUSION}

Family engagement is an important aspect of the holistic management of patients with mental illness. Despite its challenges, family engagement for patients with mental illness has demonstrated benefits in several patient outcomes. The primary care provider possesses several distinctive characteristics that offer an advantage to successfully engaging the family, such as accessibility, better rapport and less associated stigma. Primary care providers in the community could engage the family in various ways, such as providing psychoeducation, supporting the family's physical, emotional and social needs, and conducting family assessments or family therapy. The provision of education and training in mental healthcare for primary care providers and the enhancement of infrastructural capabilities to provide mental healthcare in the community are steps in the right direction.

\section{REFERENCES}

1. Amato PR, Sobolewski JM. The effects of divorce and marital discord on adult children's psychological well-being. Am Sociol Rev 2001; 66:900-21.

2. Barrera M Jr, Li SA, Chassin L. Effects of parental alcoholism and life stress on Hispanic and non-Hispanic Caucasian adolescents: a prospective study. Am J Community Psychol 1995; 23:479-507.

3. Gilman SE, Kawachi I, Fitzmaurice GM, Buka SL. Family disruption in childhood and risk of adult depression. Am J Psychiatry 2003; 160:939-46.

4. Aseltine RH Jr. Pathways linking parental divorce with adolescent depression. J Health Soc Behav 1996; 37:133-48.

5. Cherlin AJ, Furstenberg FF Jr, Chase-Lansdale L, et al. Longitudinal studies of effects of divorce on children in Great Britain and the United States. Science $1991 ; 252: 1386-9$.

6. Catalano RF, Morrison DM, Wells EA, et al. Ethnic differences in family factors related to early drug initiation. J Stud Alcohol 1992; 53:208-17.

7. Turner RA, Irwin CE, Millstein SG. Family structure, family processes, and experimenting with substances during adolescence. J Res Adolesc 1991; 1:93-106.

8. Steinberg L, Mounts NS, Lamborn SD, Dornbusch SM. Authoritative parenting and adolescent adjustment across varied ecological niches. J Res Adolesc 1991; $1: 19-36$.

9. Aquilino WS, Supple AJ. Long-term effects of parenting practices during adolescence on well-being outcomes in young adulthood. J Fam Issues 2001; 22:289-308.
10. Adlaf EM, Ivis FJ. Structure and relations: the influence of familial factors on adolescents substance use and delinquency. J Child Adolesc Subst Abuse 1996; 5:1-19.

11. McKeown RE, Garrison CZ, Jackson KL, et al. Family structure and cohesion, and depressive symptoms in adolescents. J Res Adolesc 1997; 7:267-81.

12. Cramer D. Social support and psychological distress in women and men. Br J Med Psychol 1991; 64(Pt 2):147-58.

13. Patten CA, Gillin JC, Farkas AJ, et al. Depressive symptoms in California adolescents: family structure and parental support. J Adolesc Health 1997; 20:271-8.

14. Mason WA, Windle M. Family, religious, school and peer influences on adolescent alcohol use: a longitudinal study. J Stud Alcohol 2001; 62:44-53.

15. Duer S, Schwenk TL, Coyne JC. Medical and psychosocial correlates of selfreported depressive symptoms in family practice. J Fam Pract 1988; 27:609-14.

16. Barrett AE, Turner RJ. Family structure and mental health: the mediating effects of socioeconomic status, family process, and social stress. J Health Soc Behav 2005; 46:156-69.

17. Dirik A, Sandhu S, Giacco D, et al. Why involve families in acute mental healthcare? A collaborative conceptual review. BMJ Open 2017; 7:e017680.

18. The National Child Traumatic Stress Network. Family Engagement and Involvement in Trauma Mental Health. June 2017. Available at: https://www. nctsn.org/sites/default/files/resources/fact-sheet/cac_family_engagement_and_ involvement_in_trauma_mental_health.pdf. Accessed November 28, 2020.

19. Eassom E, Giacco D, Dirik A, Priebe S. Implementing family involvement in the treatment of patients with psychosis: a systematic review of facilitating and hindering factors. BMJ Open 2014; 4:e006108.

20. Epidemiology and Disease Control Division, Ministry of Health, Singapore. National Health Survey 2010. Available at: https://www.moh.gov.sg/docs/ librariesprovider5/resources-statistics/reports/nhs2010---low-res.pdf. Acessed June 11, 2020.

21. Chan A, Østbye T, Malhotra R, Hu AJ. The Survey on Informal Caregiving. 2010. In: Ministry of Social and Family Development. Available at: https:// www.msf.gov.sg/publications/Pages/The-Survey-on-Informal-Caregiving.aspx. Accessed June 11, 2020.

22. Wallcraft J, Amering M, Freidin J, et al. Partnerships for better mental health worldwide: WPA recommendations on best practices in working with service users and family carers. World Psychiatry 2011; 10:229-36.

23. World Health Organization. Mental Health Action Plan 2013-2020. Available at: https://www.who.int/publications/i/item/9789241506021. Accessed May 6, 2020.

24. Royal College of Psychiatrists Social Inclusion Scoping Group. Mental health and social inclusion: making psychiatry and mental health services fit for the 21st century. Position statement PS01/2009. June 2009. Available at: https:// www.rcpsych.ac.uk/docs/default-source/mental-health/work-and-mentalhealth-library/position-statement-2009.pdf?sfvrsn=97bca29e_2. Accessed May 6, 2020.

25. 3rd Enabling Masterplan Steering Committee. 3rd enabling masterplan $2017-$ 2021: caring nation, inclusive society. In: SG Enable [online]. Available at: https://www.sgenable.sg/pages/content.aspx?path=/about-us/enablingmasterplan/. Accessed May 6, 2020.

26. Falloon IRH, Held T, Coverdale JH, Roncone R, Laidlaw TM. Family interventions for schizophrenia: a review of long-term benefits of international studies. Psychiatr Rehabil Skills 1999; 3:268-90.

27. Pilling S, Bebbington P, Kuipers $E$, et al. Psychological treatments in schizophrenia: I. Meta-analysis of family intervention and cognitive behaviour therapy. Psychol Med 2002; 32:763-82.

28. Randolph ET, Eth S, Glynn SM, et al. Behavioural family management in schizophrenia. Outcome of a clinic-based intervention. Br J Psychiatry 1994; 164:501-6.

29. Tarrier N, Barrowclough C, Porceddu K, Fitzpatrick E. The Salford Family Intervention Project: relapse rates of schizophrenia at five and eight years. $\mathrm{Br}$ J Psychiatry 1994; 165:829-32.

30. Miklowitz DJ, Simoneau TL, George EL, et al. Family-focused treatment of bipolar disorder: 1-year effects of a psychoeducational program in conjunction with pharmacotherapy. Biol Psychiatry 2000; 48:582-92.

31. Shimazu K, Shimodera S, Mino Y, et al. Family psychoeducation for major depression: randomised controlled trial. Br J Psychiatry 2011; 198:385-90.

32. Pharoah F, Mari J, Rathbone J, Wong W. Family intervention for schizophrenia. Cochrane Database Syst Rev 2010; (12):CD000088.

33. Xiong W, Phillips MR, Hu X, et al. Family-based intervention for schizophrenic patients in China. A randomised controlled trial. Br J Psychiatry 1994; 165:239-47.

34. Honig A, Hofman A, Rozendaal N, Dingemans P. Psycho-education in bipolar disorder: effect on expressed emotion. Psychiatry Res 1997; 72:17-22.

35. Fleury MJ, Grenier G, Caron J, Lesage A. Patients' report of help provided by relatives and services to meet their needs. Community Ment Health J 2008; 44:271-81

36. Schofield N, Quinn J, Haddock G, Barrowclough C. Schizophrenia and substance misuse problems: a comparison between patients with and without 
significant carer contact. Soc Psychiatry Psychiatr Epidemiol 2001; 36:523-8.

37. Glick ID, Stekoll AH, Hays S. The role of the family and improvement in treatment maintenance, adherence, and outcome for schizophrenia. J Clin Psychopharmacol 2011; 31:82-5.

38. Herz MI, Lamberti JS, Mintz J, et al. A program for relapse prevention in schizophrenia: a controlled study. Arch Gen Psychiatry 2000; 57:277-83.

39. Falloon IRH, Shanahan W, Laporta M. Prevention of major depressive episodes: early intervention with family-based stress management. J Ment Health 1992 1:53-60.

40. Norman RMG, Malla AK, Manchanda R, et al. Social support and three-year symptom and admission outcomes for first episode psychosis. Schizophr Res 2005; 80:227-34.

41. Tempier R, Balbuena L, Lepnurm M, Craig TKJ. Perceived emotional support in remission: results from an 18-month follow-up of patients with early episode psychosis. Soc Psychiatry Psychiatr Epidemiol 2013; 48:1897-904.

42. Barrowclough C, Tarrier N, Lewis S, et al. Randomised controlled effectiveness trial of a needs-based psychosocial intervention service for carers of people with schizophrenia. Br J Psychiatry 1999; 174:505-11.

43. Tarrier N, Barrowclough C, Vaughn C, et al. Community management of schizophrenia. A two-year follow-up of a behavioural intervention with families. Br J Psychiatry 1989; 154:625-8.

44. McFarlane WR, Link B, Dushay R, Marchal J, Crilly J. Psychoeducational multiple family groups: four-year relapse outcome in schizophrenia. Fam Process 1995; 34:127-44.

45. Leff J, Kuipers L, Berkowitz R, Sturgeon D. A controlled trial of social intervention in the families of schizophrenic patients: two year follow-up. Br J Psychiatry 1985; 146:594-600.

46. Bergner E, Leiner AS, Carter T, et al. The period of untreated psychosis before treatment initiation: a qualitative study of family members' perspectives. Compr Psychiatry 2008; 49:530-6.

47. Fridgen GJ, Aston J, Gschwandtner U, et al. Help-seeking and pathways to care in the early stages of psychosis. Soc Psychiatry Psychiatr Epidemiol 2013; 48:1033-43.

48. McFarlane WR, Dushay RA, Stastny P, Deakins SM, Link B. A comparison of two levels of family-aided assertive community treatment. Psychiatr Serv 1996 47:744-50.

49. Zhang M, Yan H, Yao C, et al. Effectiveness of psychoeducation of relatives of schizophrenic patients: a prospective cohort study in five cities of China. Int Ment Health 1993; 22:47-59.

50. Stam H, Cuijpers P. Effects of family interventions on burden of relatives of psychiatric patients in the Netherlands: a pilot study. Community Ment Health 2001; 37:179-87.

51. Cohen AN, Glynn SM, Hamilton AB, Young AS. Implementation of a family intervention for individuals with schizophrenia. J Gen Intern Med 2010; 25 Suppl 1:32-7.

52. Peters S, Pontin E, Lobban F, Morriss R. Involving relatives in relapse prevention for bipolar disorder: a multi-perspective qualitative study of value and barriers. BMC Psychiatry 2011; 11:172.

53. Allen J, Burbach F, Reibstein J. 'A different world' individuals' experience of an integrated family intervention for psychosis and its contribution to recovery. Psychol Psychother 2013; 86:212-28.

54. Piippo J, Aaltonen J. Mental health and creating safety: the participation of relatives in psychiatric treatment and its significance. J Clin Nurs 2009; 18:2003-12

55. Budd RJ, Hughes IC. What do relatives of people with schizophrenia find helpfu about family intervention? Schizophr Bull 1997; 23:341-7.

56. Vaingankar JA, Fong CW, Kwok KW, et al. Managing patients with mental illness in primary care: apprehensions and views of general practitioners. Singapore Fam Physician 2010; 36:22-5.

57. Allen RE, Read J. Integrated mental health care: practitioners' perspectives. Aust N Z J Psychiatry 1997; 31:496-503.

58. Michie S, Pilling S, Garety P, et al. Difficulties implementing a mental health guideline: an exploratory investigation using psychological theory. Implement Sci 2007; 2:8.

59. Butler MP, Begley M, Parahoo K, Finn S. Getting psychosocial interventions into mental health nursing practice: a survey of skill use and perceived benefits to service users. J Adv Nurs 2014; 70:866-77.

60. Brent BK, Giuliano AJ. Psychotic-spectrum illness and family-based treatments: a case-based illustration of the underuse of family interventions. Harv Rev Psychiatry 2007; 15:161-8.

61. World Health Organization. Declaration of Alma-Ata. September 1978. Available at: https://www.who.int/publications/almaata_declaration en.pdf?ua=1. Accessed June 11, 2020

62. World Health Organization. Declaration of Astana. October 2018. Available at: https://www.who.int/docs/default-source/primary-health/declaration/gcphcdeclaration.pdf. Accessed June 11, 2020.

63. World Health Organization. Primary health care. February 2019. Available at: https://www.who.int/news-room/fact-sheets/detail/primary-health-care. Accessed June 11, 2020
64. Subramaniam M, Abdin E, Vaingankar JA, et al. Tracking the mental health of a nation: prevalence and correlates of mental disorders in the second Singapore mental health study. Epidemiol Psychiatr Sci 2019; 29:e29.

65. Ong B. Inaugural Chee Kuan Tsee Lecture: mental health care for the $21 \mathrm{st}$ century. Ann Acad Med Singap 2017; 46:258-62.

66. Agency of Integrated Care, Singapore. Mental health GP partnership programme. Available at: https://www.primarycarepages.sg/Documents/Practice Management/MHGPP Brochure 2017_FA.pdf. Accessed June 7, 2020.

67. Lum AW, Kwok KW, Chong SA. Providing integrated mental health services in the Singapore primary care setting--the general practitioner psychiatric programme experience. Ann Acad Med Singap 2008; 37:128-31.

68. What is primary care mental health? WHO and Wonca Working Party on Mental Health. Ment Health Fam Med 2008; 5:9-13.

69. Schomerus G, Angermeyer MC. Stigma and its impact on help-seeking for mental disorders: what do we know? Epidemiol Psichiatr Soc 2008; 17:31-7.

70. Fleury MJ, Imboua A, Aubé D, Farand L, Lambert Y. General practitioners' management of mental disorders: a rewarding practice with considerable obstacles. BMC Fam Pract 2012; 13:19.

71. Henderson C, Evans-Lacko S, Thornicroft G. Mental illness stigma, help seeking, and public health programs. Am J Public Health 2013; 103:777-80.

72. Corrigan PW, Druss BG, Perlick DA. The impact of mental illness stigma on seeking and participating in mental health care. Psychol Sci Public Interest 2014; 15:37-70.

73. Godoy L, Hodgkinson S, Robertson HA, et al. Increasing mental health engagement from primary care: the potential role of family navigation. Pediatrics 2019; 143:e20182418.

74. Lai YM, Hong CP, Chee CY. Stigma of mental illness. Singapore Med J 2001; 42:111-4.

75. Pang S, Liu J, Mahesh M, et al. Stigma among Singaporean youth: a crosssectional study on adolescent attitudes towards serious mental illness and social tolerance in a multiethnic population. BMJ Open 2017; 7:e016432.

76. Yesufu-Udechuku A, Harrison B, Mayo-Wilson E, et al. Interventions to improve the experience of caring for people with severe mental illness: systematic review and meta-analysis. Br J Psychiatry 2015; 206:268-74.

77. McFarlane WR. Family interventions for schizophrenia and the psychoses: a review. Fam Process 2016; 55:460-82.

78. Asher L, Patel V, De Silva MJ. Community-based psychosocial interventions for people with schizophrenia in low and middle-income countries: systematic review and meta-analysis. BMC Psychiatry 2017; 17:355.

79. Schulz R, Sherwood PR. Physical and mental health effects of family caregiving. Am J Nurs 2008; 108(9 Suppl):23-7.

80. Vitaliano PP, Zhang J, Scanlan JM. Is caregiving hazardous to one's physical health? A meta-analysis. Psychol Bull 2003; 129:946-72.

81. Pinquart M, Sörensen S. Differences between caregivers and noncaregivers in psychological health and physical health: a meta-analysis. Psychol Aging 2003; 18:250-67.

82. Pinquart M, Sörensen S. Correlates of physical health of informal caregivers: a meta-analysis. J Gerontol B Psychol Sci Soc Sci 2007; 62:P126-37.

83. Schulz R, O’Brien AT, Bookwala J, Fleissner K. Psychiatric and physical morbidity effects of dementia caregiving: prevalence, correlates, and causes. Gerontologist 1995; 35:771-91.

84. Biegel DE, Sales E, Schulz R. Family caregiver applications. In: Family caregiving in chronic illness: Alzheimer's disease, cancer, heart disease, mental illness, and stroke. Newbury Park, CA: Sage Publications, 1991.

85. Haley WE, Levine EG, Brown SL, Bartolucci AA. Stress, appraisal, coping, and social support as predictors of adaptational outcome among dementia caregivers. Psychol Aging 1987; 2:323-30.

86. Fadden G, Bebbington $\mathrm{P}$, Kuipers $\mathrm{L}$. The burden of care: the impact of functional psychiatric illness on the patient's family. Br J Psychiatry 1987; 150:285-92.

87. Maurin JT, Boyd CB. Burden of mental illness on the family: a critical review. Arch Psychiatr Nurs 1990; 4:99-107.

88. Gutiérrez-Maldonado J, Caqueo-Urízar A, Kavanagh DJ. Burden of care and general health in families of patients with schizophrenia. Soc Psychiatry Psychiatr Epidemiol 2005; 40:899-904.

89. Heider D, Angermeyer MC, Winkler I, et al. A prospective study of quality of life in schizophrenia in three European countries. Schizophr Res 2007: 93:194-202.

90. Möller-Leimkühler AM, Obermeier M. Predicting caregiver burden in first admission psychiatric patients. 2-year follow-up results. Eur Arch Psychiatry Clin Neurosci 2008; 258:406-13.

91. Caqueo-Urízar A, Gutiérrez-Maldonado J, Miranda-Castillo C. Quality of life in caregivers of patients with schizophrenia: a literature review. Health Qual Life Outcomes 2009; 7:84.

92. Kimura H, Tamoto T, Kanzaki N, Shinchi K. Burnout and characteristics of mental health of caregivers of elderly dementia patients. J Rural Med 2011; 6:47-53.

93. Allen J, Balfour R, Bell R, Marmot M. Social determinants of mental health. Int Rev Psychiatry 2014; 26:392-407.

94. Patel V, Crick L, Hatherill S, et al. Mental disorders: equity and social determinants. In: Blas E, Kurup AS, eds. Equity, Social Determinants and Public 
Health Programmes. Geneva: World Health Organization, 2010: 115-34.

95. Fryers T, Melzer D, Jenkins R, Brugha T. The distribution of the common mental disorders: social inequalities in Europe. Clin Pract Epidemiol Ment Health 2005; 1:14.

96. Lund C, Breen A, Flisher AJ, et al. Poverty and common mental disorders in low and middle income countries: a systematic review. Soc Sci Med 2010; 71:517-28.

97. Drew N, Funk M, Tang S, et al. Human rights violations of people with mental and psychosocial disabilities: an unresolved global crisis. Lancet 2011;
378:1664-75.

98. Ingoldsby EM. Review of interventions to improve family engagement and retention in parent and child mental health programs. J Child Fam Stud 2010; 19:629-45.

99. Oyama O, Burg MA, Fraser K, Kosch SG. Mental health treatment by family physicians: current practices and preferences. Fam Med 2012; 44:704-11.

100. Graduate Diploma in Mental Health. In: Institute of Mental Health, Singapore [online]. Available at: https://www.imh.com.sg/GDMH/. Accessed November 10, 2020.

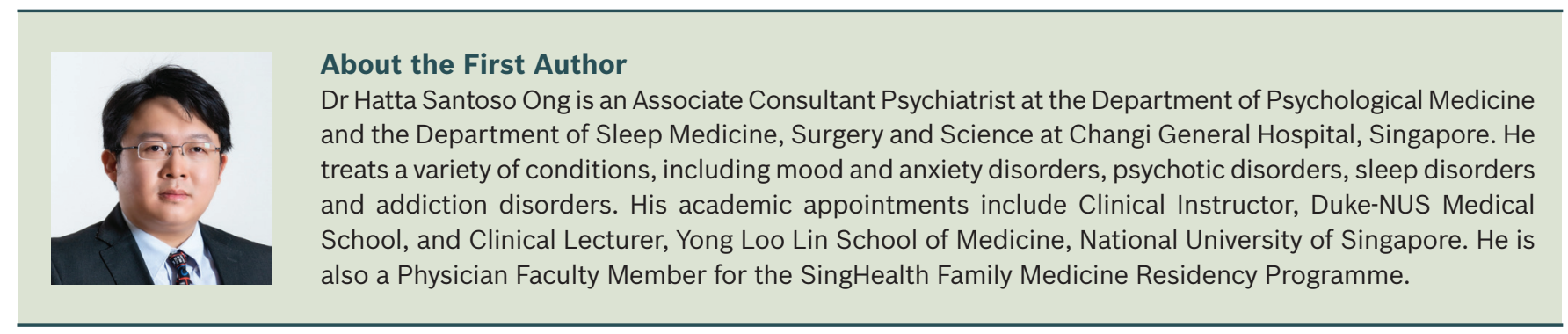

